\title{
As forças sociais de estrutura, estética e movimento: A dinâmica da apropriação do Parque Cachoeira
}

\author{
Simone Rechia* \\ Karine do Rocio Vieira dos Santos** \\ Aline Tschoke $e^{* * *}$
}

\begin{abstract}
Resumo: O Parque Cachoeira é culturalmente um dos espaços públicos mais significativos do Município de Araucária - PR, região metropolitana de Curitiba, no que se refere ao campo do lazer. O objetivo deste trabalho foi investigar quais as forças sociais, presentes no Parque Cachoeira e qual a relevância delas quanto à apropriação desse espaço. Para tanto utilizamos os seguintes passos metodológicos: (1) levantamento bibliográfico, (2) mapeamento e observações do Parque Cachoeira, (3) entrevistas com usuários do Parque. A partir do diagnóstico levantado, destacamos nesse trabalho as seguintes forças sociais, entre outras estudadas, presentes no Parque Cachoeira, que colocam em movimento a inércia social: infra-estrutura, estética e movimento.
\end{abstract}

Palavras- chave: Centros de convivência e lazer. Meio social. Participação cidadã.

\section{Ponto de PARTIDA}

A reflexão aqui desenvolvida sobre a dinâmica da apropriação ocorrida no Parque Cachoeira ${ }^{1}$ teve como ponto de partida para a análise a metáfora com o conceito físico da inércia, que deu origem ao termo da "inércia social".

O princípio físico da inércia é dependente de forças, sejam elas de impulsão, resistência, velocidade, gravidade e etc., nesse sentido,

\footnotetext{
*Departamento de Educação Física. Universidade Federal do Paraná. Curitiba, Paraná, Brasil. E-mail: simone@ufpr.br

**Departamento de Educação Física. Universidade Federal do Paraná. Curitiba, Paraná, Brasil. E-mail: karine_ufpr@yahoo.com.br

***Departamento de Educação Física. Universidade Federal do Paraná. Curitiba, Paraná, Brasil. Instituto Federal do Paraná. Paranaguá, Paraná, Brasil. E-mail: aline_tschoke@yahoo.com.br

${ }^{1}$ Principal Parque destinado ao lazer da Cidade de Araucária/PR, localizado na Rua Ceará, nํ6 65
} 
de forma metafórica, admitimos a existência da tendência da inércia social, a qual também dependerá de forças atuantes. Na metáfora utilizada estas forças serão denominadas forças sociais, compreendidas como,

Ações individuais e coletivas emergentes da sociedade, que de alguma forma, irão agir sobre a mesma. Tomando o caso específico dos espaços públicos constituídos no âmbito do lazer, isso ocorre em dois sentidos: na apropriação ou na desapropriação por meio de diversificadas práticas sócio-culturais. (VIEIRA DOS SANTOS; RECHIA; TSCHOKE; VIEIRA, 2011, p. 3)

Percebemos que as forças sociais atuam a todo instante de forma simultânea. Vale ressaltar que:

Nesse plano (social), não há leis estanques, sendo assim não se trata de uma lógica de ação e reação. $\mathrm{O}$ princípio da inércia, nesse caso, não poderia ser utilizado na sua forma original para descrever um fenômeno sociológico, visto que a lei da física é uma regra geral, enquanto a "inércia social" referese a singularidade de cada local. Esta visão parte do pressuposto de que cada pessoa possui sua individualidade e certo nível de autonomia perante suas escolhas. Os sujeitos muitas vezes podem escolher onde querem ou não estar, mas precisamos atentar para o fato dessas escolhas serem construídas historicamente pelo indivíduo e influenciadas pela sociedade na qual está inserido. Percebemos também que o movimento ou o vazio gerado nos espaços de lazer pode ser iniciado ou retido por diversas questões, dentre elas a violência, a moda vigente, insegurança, hábitos, autonomia individual. (VIEIRA DOS SANTOS; RECHIA; TSCHOKE; VIEIRA, 2011, p. 3)

Tendo em vista essa metáfora como uma possibilidade de análise da dinâmica da apropriação dos espaços públicos de lazer, voltamos nosso olhar para os parques urbanos, visto que são importantes 
espaços públicos de lazer no que se refere a "[...] materialidade urbana da cidade, os quais associam preservação ambiental e experiências de lazer". (RECHIA 2003, p.2).

Em face desse sentido dos parques urbanos, o objetivo deste trabalho é investigar quais as forças sociais e qual a relevância delas quanto à apropriação desse espaço de lazer, especificamente no Parque Cachoeira localizado no município de Araucária - PR, região metropolitana de Curitiba. A apropriação dos espaços urbanos elemento central deste trabalho (na relação com as forças sociais) compreende um debate já em andamento. De acordo com Codina (2007) apropriação é "[...] sentimiento de poseer y gestionar un espacio, independientemente de su propiedad legal, por uso habitual o por identificación" (apud NUNES JUNIOR, AMARAL, 2009, p. 5). Isto é, a apropriação remete ao sentimento de que o local lhe é próprio. Para Pol (1996, p. 45; NUNES JUNIOR, AMARAL, 2009, p. 5) "La apropiación del espacio - con toda su complejidad - aparece como uno de los núcleos centrales en la interacción entre el ser humano y su entrono físico".

Percebemos então que o termo apropriação nos remete a um sentido de interação física do sujeito com determinado local na presença do sentimento subjetivo para com este espaço, o pertencimento. Este sentimento irá modificar a relação que o sujeito estabelece com o espaço de forma que quando há o sentimento de pertencimento ele se torna um lugar ${ }^{2}$.

Dessa forma percebemos que o pertencimento e as formas de apropriação estão muito próximos do ponto de vista conceitual, pois tratam da relação indivíduo-espaço.

Um exemplo de apropriação do Parque que ajudou a pensar o trabalho ocorreu na Academia da Terceira Idade recém-inaugurada, na qual um homem que nitidamente não era responsável pela manutenção do parque contribuiu para isso colocando massa epóxi

2Para o autor, o lugar expressa relações de ordem objetiva em articulação com relações subjetivas, relações verticais resultado do poder hegemônico, imbricadas com relações horizontais de coexistência e resistência. Daí a força do lugar. (RECHIA, 2003, p. 35) 
nos parafusos da academia. Com esse exemplo buscamos mostrar como as forças sociais influem na apropriação, no caso citado a estrutura do parque impulsionou a apropriação do homem, no sentido de que ele pode materializar seu sentimento de pertencimento ao, por sua vontade, intervir na manutenção do espaço. Com isso reiteramos nossa problemática que é investigar as forças sociais e qual a relevância delas quanto à apropriação no Parque Cachoeira.

Mesmo que alguns autores, tais como Marcellino (1998), Bramante (1998), Mascarenhas (2005), Pacheco (2006), Stigger (2002), Amaral (2003); em Curitiba: Rechia (2003), França (2007), Cagnato (2007), Gonçalves (2008), Gonzaga (2010), venham demonstrando interesse em discutir as formas de apropriação dos espaços e equipamentos de lazer, acreditamos que este estudo trará novas contribuições para pesquisas na área, e a possibilidade de gerar reflexões que possam ser aplicáveis ao cotidiano das grandes cidades, devido às especificidades a que se propõem, bem como contribuir para a elaboração de programas sociais e formulação de novas políticas públicas para o lazer.

\section{Caminhos metodológicos}

A presente pesquisa, realizada a partir de um olhar "de perto" e "de dentro" do Parque Cachoeira privilegiou os atores sociais comuns encontrados no cotidiano desse espaço público de lazer. Dessa forma optamos por um olhar qualitativo de pesquisa, baseado em dados de observação e entrevistas semi-estruturadas, visto que esses métodos nos permitiram olhar para as minúcias do Parque Cachoeira e "[...] captar determinados aspectos da dinâmica urbana que passariam despercebidos, se enquadrados exclusivamente pelo enfoque das visões macro e dos grandes números" (MAGNANI, 2002, p. 16).

Orientada pelo seu questionamento central, esta pesquisa foi desenvolvida nas seguintes etapas metodológicas: (1) Mapeamento do Parque de acordo com o protocolo de observação dos espaços e 
equipamentos de esporte e lazer, formulado pelo GEPLEC- Grupo de Estudos e Pesquisa em Espaço, Lazer e Cidade $^{3}$, tendo assim uma visão detalhada de aspectos históricos, de acessibilidade, organização do espaço físico, formas de usos, dentre outros; (2) Observações sistemáticas realizadas em 12 visitas ao Parque de aproximadamente 1 hora cada, registradas em diário de campo e registros fotográficos; (3) Entrevistas semi-estruturadas com vinte e sete usuários do Parque. A escolha dos participantes se deu aleatoriamente, contemplando diferentes gêneros e idades ${ }^{4}$. (4) Interpretação dos dados, buscando as particularidades, e fazendo nossas inferências até chegar nas categorias de análise com a triangulação dos dados empíricos, buscando atender ao objetivo geral da pesquisa. Essa etapa foi composta pela descrição, análise e interpretação dos dados coletados:

[... ] na descrição as opiniões dos informantes são apresentadas da maneira mais fiel possível, como se os dados falassem por si próprios; na análise o propósito é ir além do descrito,fazendo uma decomposição dos dados e buscando as relações entre as partes que foram decompostas e, por último, na interpretação - que pode ser feita após a análise ou após a descrição -buscam-se sentidos das falas e das ações para se chegar a uma compreensão ou explicação que vão além do descrito e analisado.(GOMES, 2011, p.80)

A partir da coleta de dados, neste caso realizada durante um estudo de monografia das autoras, intitulado "Forças sociais no parque cachoeira em Araucária- PR: conexões entre estrutura físicaespacial, cultura local e formas de apropriação", foram elencadas seis forças sociais que percebemos atuantes como propulsoras da apropriação do Parque Cachoeira: a estrutura, estética, movimento,

\footnotetext{
${ }^{3}$ Coordenado pela Professora Pós-Doutora Simone Rechia, no Departamento de Educação Física da Universidade Federal do Paraná.

${ }^{4}$ Dentre os entrevistados estavam seis adolescentes com idade entre 10 a 19 anos (três meninas e três meninos), seis adultos jovens, com idade entre 20 à 39 anos (três mulheres e três homens), nove adultos de meia idade com variação de 40 á 59 anos (cinco mulheres e quatro homens) além de seis idosos (três mulheres e três homens) com idades superior a 60 anos. As entrevistas foram gravadas e transcritas na integra, visando a percepção de todos os detalhes das falas.
} 
segurança, liderança e pertencimento. Porém, nesse artigo nos limitaremos a discorrer sobre as três primeiras, selecionadas pela sua centralidade na reflexão da apropriação no parque.

\section{As forças socials atuantes no Parque Cachoeira: a ESTRUTURA}

A estrutura pode ser vista como uma força social na medida em que é planejada e executada por determinadas pessoas ou instituições. No caso do Parque Cachoeira quem executa esse planejamento é a Prefeitura Municipal, mais especificamente a Secretaria Municipal do Meio Ambiente (SMMA), a qual tem sua sede no interior do Parque.

$\mathrm{Na}$ figura a seguir é possível através da legenda perceber diversos atrativos do Parque: (1) Gramado, (2) Gramado, (3) Gramado, (4) Campo de futebol e Pista de Corrida, Academia da Terceira idade, (6) Quadras de cimento, (7) Parquinho e Mirante do Lago, (8) Museu Tingui-Cuera e casa do Artesanato, (9) Aldeia da Solidariedade, (10) Bosque com Churrasqueiras, (11) Ginásio Joval de Paula Souza, (12) Quadra de cimento e (13) Ponte da Cachoeira.

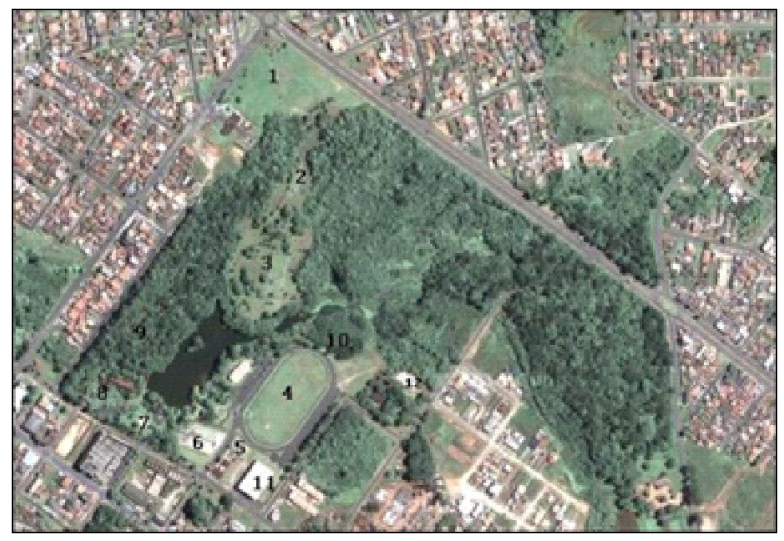

Figura1 - Vista panorâmica do Parque Cachoeira.

Fonte: Google maps, 2010. 
Através da figura verificamos o amplo espaço do Parque, que conta de acordo com a Prefeitura Municipal (2010) com 300.000 $\mathrm{m}^{2}$, uma grande diversidade de equipamentos presentes, os quais servem a diferentes objetivos conforme o horário e dia observado.

Percebemos também uma atração entre os usos principais e os usos derivados, os usos principais são primeiro, aqueles que por si só atraem pessoas a um lugar específico porque funcionam como âncoras. Escritórios e fábricas são usos principais, moradias também. Porém apenas os usos principais não geram uma diversidade atraente, os espaços com usos principais precisam também de uma diversidade derivada, conceito esse que se aplica aos empreendimentos que surgem em consequiência da presença de usos principais, a fim de servir às pessoas atraídas pelos usos principais. (JACOBS, 2000, p. 178)

Desse modo, os conceitos de Jacobs (2000) de uso principal e usos combinados podem ser visto em prática, pois os usos principais podem ser observados no entorno do Parque como as moradias, um Colégio estadual, um Posto de Saúde e um Centro Municipal de Educação Infantil.

Interno ao Parque os usos considerados principais, em razão de "atraírem" os sujeitos ao Parque são: as aulas oferecidas na Aldeia da solidariedade e os treinos no campo de futebol e no ginásio Joval de Paula Souza e a sede da SMMA.

A estrutura do Parque Cachoeira é um diferencial na Cidade, comparada a dos outros Parques de Araucária. Dentre os quais existem o Parque do Passinho, que não é aberto a visitação, o Parque Ambiental do Passaúna, que está interditado e o Parque das Pontes, ilustrado na imagem a seguir, este é composto por um portal de entrada, alguns bancos e mirantes e "não dispõe de equipamentos de apoio ao visitante, tais como sanitários e lanchonetes" (PMA, 2010). A partir dessas informações, verificamos que o Parque Cachoeira é o único espaço público na cidade de Araucária com 
características de Parque, com uma estrutura de grande porte e com equipamentos diversificados de esporte e lazer. Como nos mostra o trecho da entrevista:

"Eu acho que para nós aqui de Araucária esse é um dos melhores lugares que tem, apesar de que tem outros lugares? Mas aqui é bom. Realmente é muito bom". (M. 50 anos, grifo nosso)

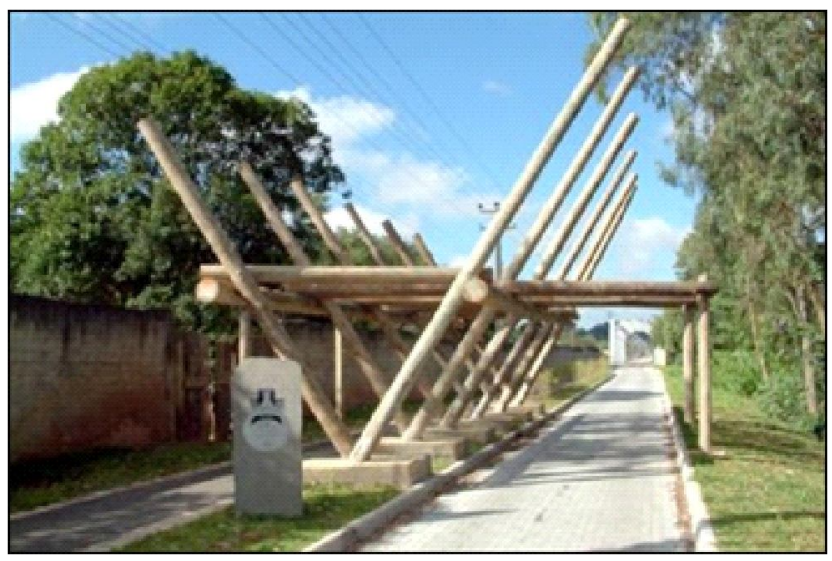

Figura 2 - Parque das pontes

Fonte: PMA (c), 2010

A estrutura do Parque se revela de tal importância para a cidade que desde pelo menos o ano de 1983 a festa típica do "Pêssego e do Ovo", retratada nas imagens a seguir, atualmente titulada apenas de "Festa do Pêssego" é realizada nesse espaço em razão de sua extensão e da boa localização geográfica na cidade, visto que está muito próximo do Centro da Cidade. Por esse motivo o Parque possui uma grande visibilidade na cidade de Araucária e inclusive nas cidades no entorno, fazendo com que o Parque seja ainda mais reconhecido. 


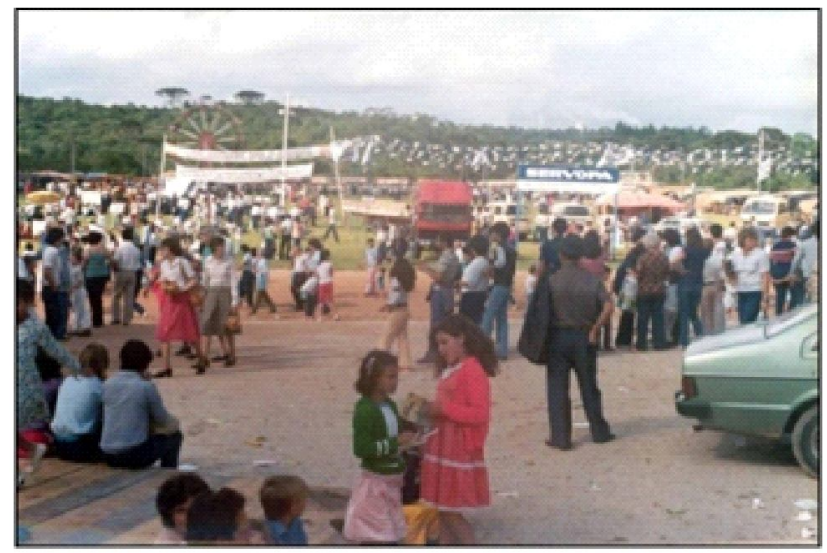

Figura 4 - Festa do pêssego e do ovo de 1983 Fonte: Oliveira Filho, 2005. P.41

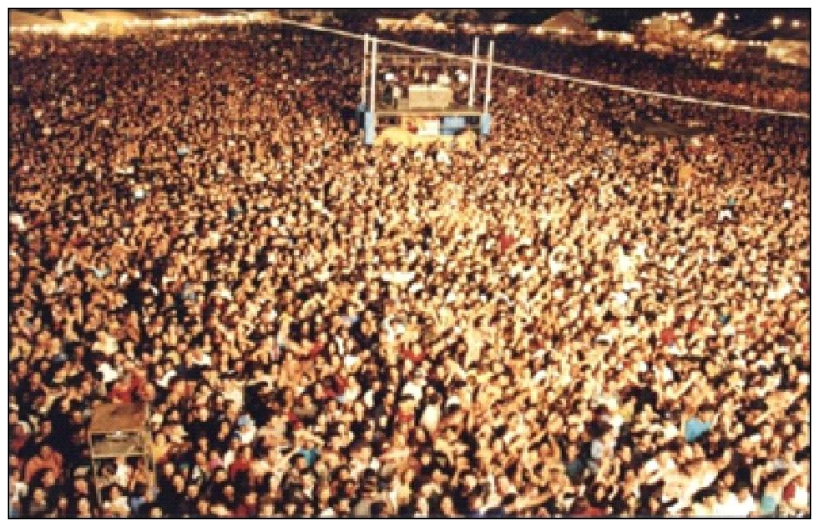

Figura 5 - Festa do pêssego e do ovo. s/d.

Fonte: Arquivo Histórico Arquelau de Almeida Torres, 2010. p.42.

Realizada sempre no mês de dezembro, a festa tem o intuito de "Divulgar e comercializar o produto e subprodutos do Município no Estado do Paraná. Além de proporcionar à população um espaço de lazer e cultura." (ARAUCÁRIA, 2010). 
Quanto a questão da estrutura podemos citar uma passagem das entrevistas com os usuários do Parque: "[...] em minha opinião, se eu morasse num lugar que não tivesse um parque igual esse aqui eu me mudaria para um lugar que tivesse [...]" (N. masculino, 52 anos)

Isso demonstra a forte relação do cidadão com a estrutura do Parque, o que deve estar relacionado com as vivências e sentimentos experienciados por ele naquele espaço ou em outros com características estruturais semelhantes.

E ainda na fala de uma usuária que é natural de Salvador - BA e está morando a três meses em Araucária, percebemos a importância de um espaço bem estruturado.

Nossa! Como lá em Salvador não tem isso eu acho que os governantes de lá poderiam se espelhar em fazer esse tipo de parque lá também, por que eu acho que os idosos, até as crianças mais gordinhas,e para a gente mesmo adulto é maravilhoso ter um parque desses na cidade. Lá não te.[...] Quando eu voltar vou mostrar para eles o projeto que eu achei muito legal. (C. 26 anos)

Dessa forma gostaríamos de salientar que uma estrutura contemplada por ações sistemáticas que utilizem espaços e equipamentos diversificados dentro da estrutura do parque, além de estabelecer relações com elementos urbanos do entorno como colégios, creches, postos de saúde, residências, podem gerar tanto a potencialização dos usos principais quanto oferecer subsídios para os usos derivados. Neste caso contribuem para que um espaço como o Parque Cachoeira tenha vida cotidiana permanente.

No Parque percebemos que espaços próximos a ele funcionam como usos principais como no caso de um dos usuários, que relatou ir ao parque toda vez que vai buscar o filho na creche, todavia se a creche não fosse próxima desse espaço isso dificilmente iria ocorrer.

Fazem parte da força da estrutura as características de acesso e acessibilidade. Compreendemos que "um ambiente acessível é aquele onde é possível o acesso." (MORAES, 2007, p. 24) Além 
disso, um ambiente inacessível pode conter diversas formas de barreiras, que se encontram classificadas em: atitudinais, físicas (fixas e dinâmicas) e de Informação. (idem, p. 25) O conceito de acessibilidade é compreendido como algo mais amplo que acesso, de Acordo como Milton Santos (1998, apud MORAES, 2007, p. 26)

Mais do que um direito à cidadania, o que está em jogo é o direito a obter da sociedade aqueles bens e serviços mínimos, sem os quais a existência não é digna. Esses bens e serviços constituem um encargo social, através das instâncias do governo, e são devido a todos. Sem isso, não se dirá que existe o cidadão.[...] A acessibilidade compulsória aos bens e serviços sociais seria uma parte obrigatória dos diversos projetos nacionais

No Parque foi possível observar que sua estrutura permite acesso físico à grande parte dos ambientes construídos. Porém alguns locais são de difícil acesso. Todavia não somente de rampas se constitui o acesso, em nenhuma das observações se encontrou adaptações no que se refere às pessoas com deficiência visual, auditiva, como sinais luminosos ou sonoros. Segundo Duarte e Cohem (2010, p. 82): "[...] os espaços inacessíveis para pessoas com deficiência ou mobilidade reduzida dificultam os processos de afeto e construção do Lugar, impedindo muito mais do que o acesso, já que interferem na sua construção identitária e na sua relação com o Outro."

E dessa forma se qualquer indivíduo, não consegue chegar a um determinado espaço, é evidente que não ocorra a apropriação.

É por essas razões que compreendemos a estrutura como uma força social, e que no parque Cachoeira tem grande influência e que impulsiona à apropriação, visto a grande estrutura que ele possui, porém necessita de melhorias, pois não é acessível a todos.

\subsection{EstÉtica}

Segundo dicionário Houaiss (2011) a etimologia da palavra estética vem do grego aesthésis e significa perceber, sentir, somado 
a isso destaca-se o termo como a harmonia das formas e/ou cores que trazem a beleza, ou numa perspectiva filosófica que aponta a conexão com a beleza sensível e a forma de comunicação da mesma. Também com uma tendência de uma época, porém em seu sentido filosófico pode ser compreendida sob diversas formas dependendo da ótica do autor que pretende-se estudar, temos como exemplos as considerações de Hegel em 1952 ou de Kant em 1993, além de outros autores.

De acordo com Tamakil (2001, p. 1) a estética é a ciência do belo, e ainda que:

$\mathrm{Na}$ arquitetura, a maneira de exprimir a beleza, expressão estética, é resolvida pelo volume e sua forma, pela estrutura, pelos materiais de acabamento, pelas cores, pelas aberturas, pelos detalhes construtivos, e também pelos ornamentos e decorações de vários períodos históricos.

Desse modo trataremos estética, como uma força social atuante nos espaços públicos de lazer, na forma de um adjetivo referente à beleza desse espaço, e às sensações e sentimentos positivos que este pode provocar em seus usuários.

Isto por que o direito ao lazer inclui o direito à apropriação dos espaços públicos destinados as práticas realizadas nesse tempo e espaço. Percebemos através das observações e entrevistas que essa apropriação é influenciada pela beleza do lugar em questão, no caso do Parque Cachoeira.

A preocupação em planejar tais locais tendo em vista a evocar boas sensações é primordial, visto que a cidade assim como seus equipamentos

[...] sin estética no es ética; El urbanismo es algo más que uma suma de recetas funcionales; La arquitectura urbana es um plus a La construcción. El plus es el sentido, El simbolismo, El placer, La emoción, lo que suscita uma reacción sensual. La ciudad Del deseo es La cuidad que se hace deseable y que estimula nuestros sentidos (BORJA, 2000, p. 28) 
Com isso percebemos que uma atitude cidadã, ou seja, uma atitude participativa no que tange à gestão, manutenção e limpeza desses espaços dependem do usuário sentir-se "integrado física e simbolicamente à cidade" (BORJA, 2000, p. 28), e assim sentir-se pertencente concretamente a determinados espaços das cidades.

Segundo Borja (2000, p. 84) a paisagem faz parte do urbanismo não como um complemento, mas sim como um elemento fundamental, isso por que a cidade densa e consolidada necessita de espaços respiráveis, precisa de beleza e de elementos que qualifiquem os espaços públicos vividos, fazendo do paisagismo ${ }^{5}$ um elemento ordenador na cidade.

Nesse sentido, de acordo com uma das usuárias quando indagada sobre os pontos positivos do Parque ela comentou que eram o Parquinho e as quadras, os quais segundo ela eram os mais "cuidados", isto é, os que recebem mais manutenção e conseqüentemente mais belos.

Outra questão relacionada à estética é a coexistência de dois tipos de área de ginástica no parque: a primeira consiste em uma área de alongamento seguindo o modelo tradicional de madeira e barras de ferro; e o segundo, mais recente, consiste em uma academia da terceira idade, ao ar livre. Este se tratando de um equipamento novo, composto por equipamentos de musculação que nas cores vermelho e azul, é esteticamente bonito, promove a interação do usuário com o equipamento visto que ele é articulado, proporcionando diversas possibilidades de movimento. Em contraste com outra área de ginástica de modelo tradicional, este equipamento se apresenta melhor esteticamente.

${ }^{5}$ Consiste na criação de espaços funcionais, agradáveis e bonitos, utilizando plantas e outros elementos decorativos. (IBRAP, 2010) 


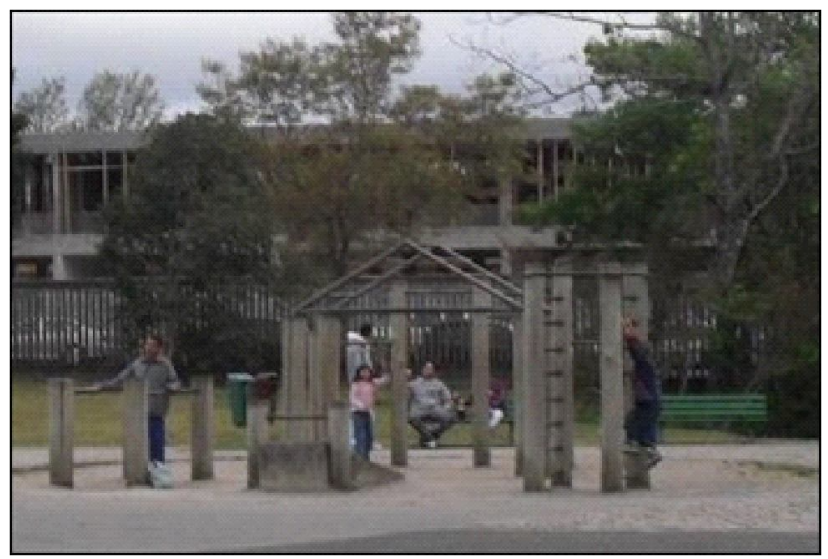

Figura 6 - Área de ginástica tradicional

Fonte: Vieira dos Santos. 2010, p.46

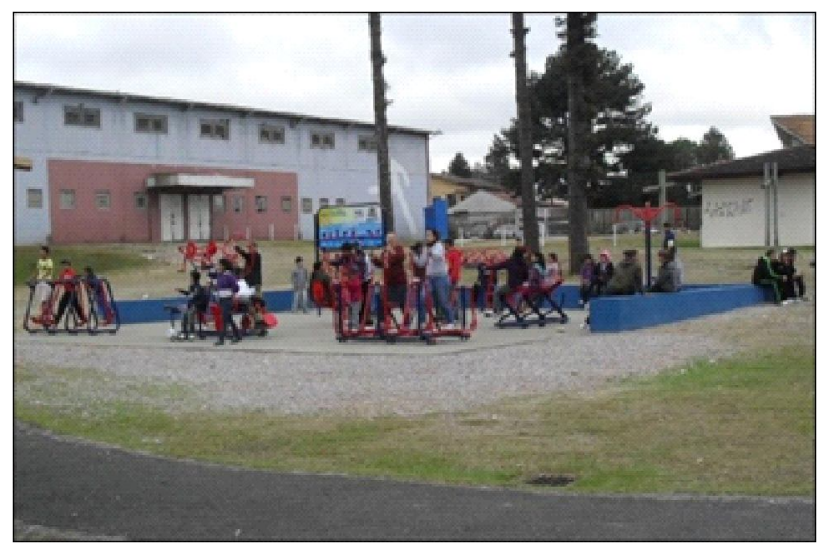

Figura 7 - Academia da terceira idade. Fonte: Vieira dos Santos, 2010, p.46

As principais diferenças entre esses dois equipamentos de semelhante objetivo são a cor, o movimento dos aparelhos, a novidade, a localização dentro do parque, os quais estimulam muito mais os sentidos que a área de ginástica com sua forma estática, sem cor, 
sem movimento e a localidade que apesar de estar próximo, parece ficar fora da área de mais movimento do parque que possui.

Durante as observações foi notável a diferença de movimento desses dois equipamentos, além do que, nas entrevistas a academia ser citada por 15 usuários num total de 26 , como um dos equipamentos mais utilizados no Parque ou como um dos pontos positivos do mesmo, já a área tradicional de ginástica não foi citada em nenhum momento.

\subsection{MOVIMENTO}

O movimento, o fluxo e permanência de pessoas em um determinado ambiente pode ser uma força de atração dos espaços de lazer de uma cidade, pois, além de gerar segurança aos presentes, sabemos que "o prazer das pessoas de ver o movimento de outras pessoas é evidente em todas as cidades". Jacobs (2000, p.40) ressalta que a origem dos espaços Públicos surge da "[...] necessidade de contato, comunicação, organização e troca [...]", sendo assim, quanto mais pessoas, mais trocas, mesmo que estas sejam apenas o encontro com o outro e com o diferente.

Percebemos também, numa menor escala, que essa força de atração tem um determinado limite, e que a partir daí converte-se em uma força de repulsão. Tal limite é atingido quando determinado espaço está saturado de movimento, e que ficar aí já não é mais agradável ou quando o público que está se apropriando não gera a segurança necessária a permanência dos sujeitos.

Através das observações notamos que um sinal para "medir" o movimento do Parque são os vendedores ambulantes ali presentes, pois essas pessoas que dependem diretamente do movimento do Parque para aumentar suas vendas possuem um grande conhecimento empírico da dinâmica do Parque e dos dias e horários em que há um maior fluxo de pessoas.

Percebemos esse fato contrastando os horários e locais de permanência desses vendedores no Parque, visto que, há mais vendedores onde há mais movimento, são eles entre o Parquinho e o lago, entre as quadras e o campo de futebol, em menor intensidade 
na entrada do Parque próxima do Ginásio e recentemente próximo da Academia da Terceira idade.

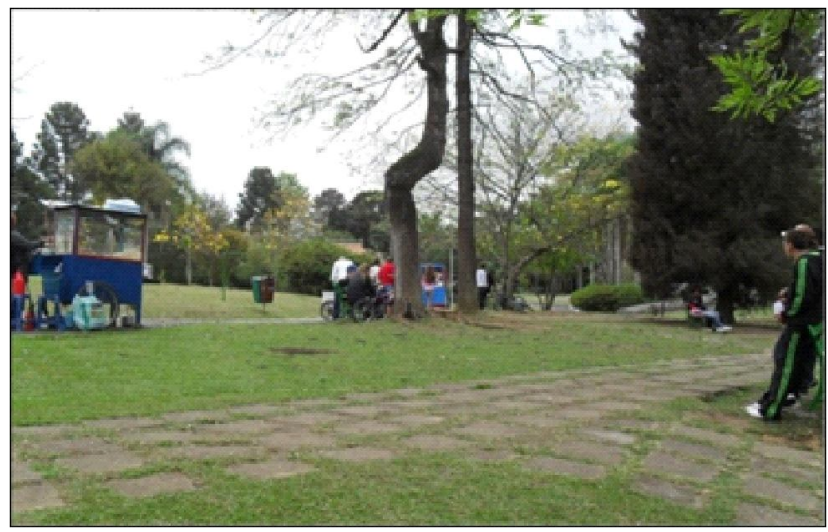

Figura 8 - Vendedores ambulantes e grupo de adolescentes comendo pipoca e olhando o movimento

Fonte: Vieira dos Santos. 2010. p.51

Uma das atividades características típicas do parque é comprar um saquinho de pipoca e consumir apreciando a paisagem e principalmente para as famílias com crianças, jogar pipocas para os gansos e patos. É nesse ponto da cultura do parque que percebemos como é fundamental para a vida desse espaço o fluxo de pessoas, a presença dos vendedores e a estrutura do espaço que permite a existência de gansos nesse local, materializando essa coexistência de forças sociais.

O movimento como força deriva ainda dos primeiros parques na Europa nos quais era comum a prática do "ver e ser visto" (SEGAWA, 1996). No Parque Cachoeira isso pode ser observado no fato de os usuários permanecerem por algum tempo nos locais onde se tem mais visibilidade do Parque e das pessoas. Alguns desses espaços são a ponte de ligação do parquinho e das quadras de cimento, a qual fica muito cheia principalmente de meninos olhando 
as meninas; o gramado "3" que dá vista para quem está saindo do campo de futebol e o "banco" que cerca a Academia da terceira idade e os bancos no entorno das quadras de cimento.

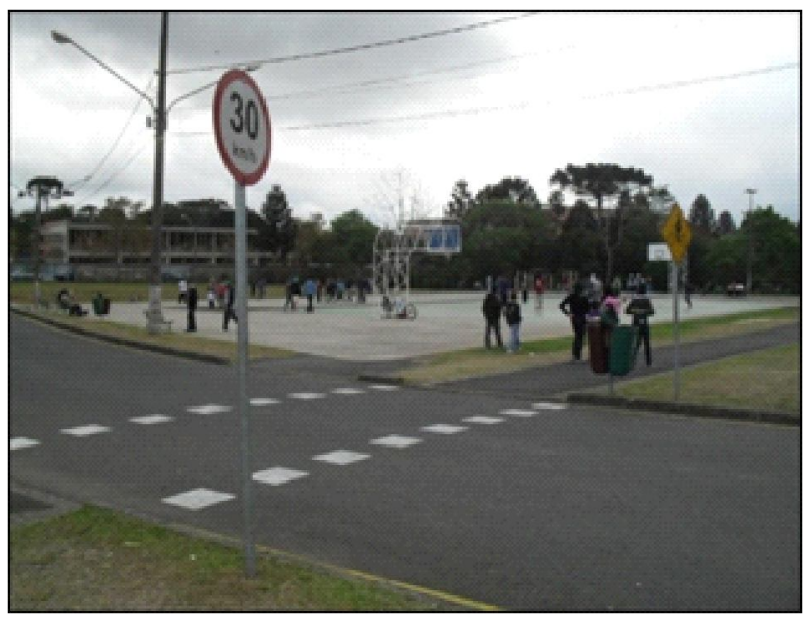

Figura 9 - Movimento do parque no domingo: quadras de cimento. Fonte: Vieira dos Santos. 2010, p.52

Além disso, é recorrente a prática do passeio, de ir de um local para outro no interior do Parque, provavelmente no intuito de ser visto pelas pessoas que ali estão, enfim um grande desfile nesse espaço público.

Esse fato pode ser observado em alguns momentos no meio de semana e de forma aguda nos fins de semana, pois é o tempo onde os usuários têm o tempo disponível de estar no Parque no qual transitam mais bem arrumados e os grupos de jovens e adolescentes e casais praticam a "paquera" o "ficar" e o namoro. 


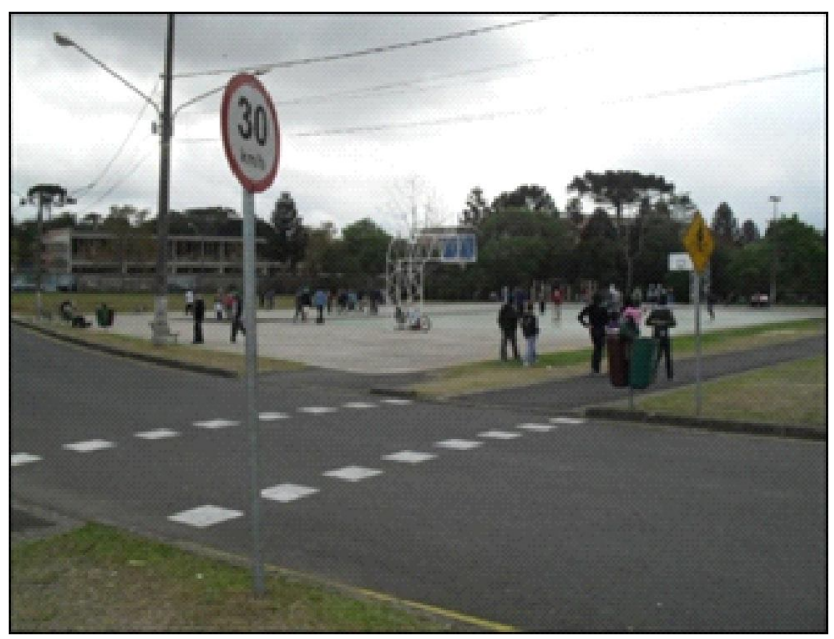

Figura 9 - Movimento do parque no domingo: quadras de cimento. Fonte: Vieira dos Santos. 2010, p.52.

Durante as entrevistas poucas pessoas responderam não vir ao parque nos fins de semana pelo fato dele estar muito cheio, muito movimentado, isso por que o principal objetivo delas era o interesse físico - esportivo. Isto é, utilizar a pista e a academia principalmente, e durante o tempo do fim de semana esses espaços são apropriados com outros objetivos, como o do passeio e da brincadeira. Nesse caso, a diferença dos objetivos dos grupos provoca essa divisão. Essa segregação pode chegar ao nível do medo e nesse tange a força social da insegurança.

\section{CONSIDERAÇõES FINAIS: CONEXÕES O COTIDIANO A APROPRIAÇÃO}

A análise da dinâmica de apropriação do Parque Cachoeira foi realizada a partir da metáfora da inércia social, pois essa formulação nos permitiu perceber que as motivações que orientam a permanência dos usuários ou não em determinados locais dependem de diversas "forças". Estas não atuam sós, mas em conjunto e simultaneamente. Por exemplo, uma das cenas vistas foi um grupo de amigos parado na ponte, comendo pipoca e olhando as meninas que passavam por 
ali. Nesse ponto percebemos nitidamente que as forças da estrutura, que os permitem permanecer numa ponte estão interferindo simultaneamente com a força do movimento, pois é possível supor que eles não estariam ali se soubessem que não haveria meninas nesse local.

Dessa forma foi possível inferir a partir da pesquisa que as três forças descritas no decorrer do artigo, a estrutura, a estética e o movimento influenciam na dinâmica da apropriação quando atraem as pessoas pelos espaços e equipamentos presentes nesse local. A estética atua no sentido de que pela beleza do Parque os usuários se sentem bem nesse local, impulsionando também sua permanência e retorno. Já o movimento opera quando usuários que vão ao parque o fazem sabendo que lá haverão outras pessoas, muitas vezes esse é o motivo principal.

Com isso notamos que as forças sociais presentes no parque pesquisado interferem diretamente nas formas de apropriação, as quais por sua vez interferem novamente nas forças sociais. Por exemplo, se o Parque Cachoeira não fosse um espaço que culturalmente tem como uma das funções principais a físico-esportiva provavelmente não teria sido instalada uma academia da Terceira Idade, isto é, a forma pela qual a população do entorno se apropriou deste espaço interferiu no modelo de equipamento que foi instalado, modificando a força social da estrutura.

A escolha dos cidadãos por estar em determinado lugar e não em outro passa por inúmeros fatores, muitas vezes não percebidos. Nesse sentido compreendendo os elementos das forças sociais, buscando elucidar como se dá a dinâmica da apropriação no Parque Cachoeira, podemos impulsionar a ação do Poder público, visando sempre à melhoria dos espaços públicos de lazer e percebendo que a dinâmica do pertencimento atua como uma força fundamental nesse processo de exercício da cidadania. 
Forces of social structure, and aesthetic movement: the dynamics of appropriation of the Cachoeira's Park

Abstract: Cachoeira's Park is culturally one of the most significant public spaces in the city of Araucaria - PR, metropolitan region of Curitiba, in relation to the field of leisure. The aim of this study was to investigate the social forces which are present in the Park Falls and the relevance of them on the appropriation of that space. For this we used the following methodological steps: (1) bibliography, (2) mapping and observations of this Park, (3) interviews with users of the park. From the diagnosis raised, in this study highlight the following social forces, among others studied in the present Cachoeira's park, which set in motion the social: infrastructure, aesthetics and movement.

Key words: Centers of connivance and leisure. Social environment, Citizen participation.

Fuerzas de la estructura social, y movimiento estético: dinámica de la propriedad del parque "Cachoeira"

Resumen: El parque "Cachoeira" es culturalmente uno de lós espacios públicos más significativos de la ciudad Araucária- PR, en la región metropolitana de Curitiba, en relación com el ámbito del ócio. El objetivo de este estúdio fue investigar las fuerzas sociales presentes en el parque "Cachoeira" y la relevancia de los mismos en la apropiación de este espacio. Por lo tanto se utilizan los seguientes pasos metodológicos:

(1) literatura; (2) mapas y observaciones del parque "Cachoeira"; (3)entrevistas con los usuários del parque. A partir del diagnóstico planteado, este estúdio destaca las siguientes fuerzas sociales, entre otros estudiados, presentes en el parque, que puso en marcha la inércia social: infraestructura, la estética y el movimiento.

Palabras clave: Centros de ócio y convivência. Medio social. Participación ciudadana. 


\section{REFERÊNCIAS}

ARAUCÁRIA. Prefeitura Municipal. Os Espaços de lazer em Araucária. 2. ed. Araucária: 2002.

ARAUCÁRIA. Prefeitura Municipal. História da Cidade. 2010c. Disponível em: http://www.araucaria.pr.gov.br/index.php?a=template.php\&ID_MATERIA=497\&tit =História. Acesso em: 16 out. 2011.

ARAUCÁRIA. Prefeitura Municipal. Parque das Pontes. 2010a. Disponível em: http://www.araucaria.pr.gov.br/index.php?ID_MATERIA=2742. Acesso em: $16 \backslash 10 \backslash 2011$.

BORJA, J. La ciudad conquistada. Madrid: Alianza. 2003.

CODINA, N. Entre el ocio, el turismo y el consumo. El tiempo y la apropiación Del tiempo. In MARTINEZ, J. R. (org.). Perspectivas y retrospectivas de la Psicología Social en los albores del siglo XXI . Madrid: Biblioteca Nueva, 2007. p. 205-214.

DE DUARTE, C. R.; COHEN, R. Acessibilidade como fator de construção do lugar. In: FERREIRA, A. B. de H. Mini Aurélio. 4.ed. Rio de Janeiro: Nova Fronteira, 2000.

GASPAR, A. Física: série brasil. São Paulo: Ática, 2007.

GOMES, R. Análise e interpretação de dados de pesquisa qualitativa. In: MINAYO, M. (Org). Pesquisa Social Teoria método e criatividade. Petrópolis, RJ: Vozes, 2011.p.9-29.

HEGEL, G. W. F. Estética. A Idéia e o Ideal. Tradução de Orlando Vitorino. Lisboa: Guimarães Editores, 1952

HOUAISS, Antonio; VILLAR, Mauro de Salles; FRANCO, Francisco Manoel de Mello. Dicionário Houaiss da língua portuguesa. Disponível em: http:// houaiss.uol.com.br. Acesso em: 16 out. 2011.

KANT, Immanuel. Crítica da faculdade do juízo. Rio de Janeiro: Forense Universitária, 1993.

JACOBS, J. Morte e vida de grandes cidades. São Paulo: Martins Fontes, 2000.

MACEDO, S.. S.; SAKATA, F. G.. Parques urbanos no Brasil. São Paulo: EDUSP; Imprensa Oficial do Estado, 2002.

MAGNANI, J. G. C. De perto e de dentro: notas para uma etnografia urbana. 
MORAES, M. C. de. Acessibilidade no Brasil: análise da NBR 9050. 2007. 175 f. Dissertação (Arquitetura e Urbanismo) - UFSC; Florianópolis.

OLIVEIRA FILHO, A. E. Levantamento dos atrativos culturais no Parque Cachoeira em Araucária: projeto 2005. 75 f. Bacharelado (Turismo). Curitiba: Centro Universitário Campos de Andrade.

POL, E. La apropiación del espacio. In ÍÑíGUEZ, L. \& POL, E. (coord.) Apropiación, Cognición y Representación Ambiental.. Barcelona: PUB, 1996. p. 45-62 (Monografías PsicoSocioAmbientales)

RECHIA, S. Parques públicos de Curitiba: a relação cidade-natureza nas experiências de lazer. 2003. 199 f. Tese (Doutorado em Educação Física) Faculdade de Educação Física,Universidade Estadual de Campinas, Campinas, Unicamp.

SEGAWA, H. Ao amor do público: jardins no Brasil. São Paulo: Studio Nobel, 1996.

TAMAKIL, T. Minha experiência sobre arquitetura. Revista da Faculdade de Engenharia e Arquitetura e Tecnologia, Ponta Grossa, v.3, n 2, p.1, dez. 2001.

VIEIRA DOS SANTOS, K. R.; RECHIA, S. ; TSCHOKE A. ; VIEIRA, F. G. L. As experiências no âmbito do lazer e o princípio da inércia: Uma analogia para pensar sobre os fatores que influenciam a apropriação dos espaços públicos. Movimento, Porto Alegre, v.17, n.1, p.117-135, 2011.

Recebido em: 10/09/2011

Aprovado em: 28.04.2012 
